University of Washington Tacoma

UW Tacoma Digital Commons

SIAS Faculty Publications

School of Interdisciplinary Arts and Sciences

$12-1-2008$

\title{
Patterns of Variation in the Influence of Natal Experience on Habitat Choice
}

Jeremy M. Davis

University of Washington Tacoma, jerdavis@uw.edu

Follow this and additional works at: https://digitalcommons.tacoma.uw.edu/ias_pub

\section{Recommended Citation}

Davis, Jeremy M., "Patterns of Variation in the Influence of Natal Experience on Habitat Choice" (2008). SIAS Faculty Publications. 558.

https://digitalcommons.tacoma.uw.edu/ias_pub/558

This Article is brought to you for free and open access by the School of Interdisciplinary Arts and Sciences at UW Tacoma Digital Commons. It has been accepted for inclusion in SIAS Faculty Publications by an authorized administrator of UW Tacoma Digital Commons. 


\title{
PATTERNS OF VARIATION IN THE INFLUENCE OF NATAL EXPERIENCE ON HABITAT CHOICE
}

\author{
Jeremy M. Davis* \\ Department of Evolution and Ecology, University of California-Davis \\ Davis, California 95616 USA \\ E-MAIL:JEDAVIS@VASSAR.EDU \\ KEYWORDS \\ early experience, habitat imprinting, habitat selection, Hopkins's host \\ selection principle, host choice, plant-herbivore interactions, natal habitat \\ preference induction, pre-imaginal conditioning
}

\section{ABSTRACT}

The experience of animals in their natal or larval habitats has long been considered a potential source of variation in the habitat choices made later during dispersal. This idea has been of particular interest to evolutionary biologists because of the role such variation plays in the formation of host races and species. However, experiments that have tested for the effect of natal experience on habitat choice have produced widely variable results, leading to disagreement about the ecological importance of these effects. Here, I review the results of experiments within a broad range of animal taxa to assess the potential sources of variation in observed effects of natal experience on habitat choice. I provide a comprehensive summary of previous studies and demonstrate that when natal experience influences habitat choice, it nearly always increases the acceptance of the natal habitat type. Furthermore, I discuss mechanisms that allow natal experience to affect later habitat choice and describe how these mechanisms are influenced by various experimental design elements, such as the life stage at which early experience is provided to subjects. I conclude by reviewing the adaptive hypotheses for why animals might or might not respond to natal experience, and also how these hypotheses might explain interspecific differences in the importance of natal experience during habitat selection decisions. By understanding in what species, and in which contexts, experience influences habitat selection, we will be able to predict the ecological and evolutionary consequences of these effects more accurately.

\section{INTRODUCTION}

I N A BROAD RANGE of animal species, experience in the natal habitat (i.e., the habitat or host in which an animal is placed by its mother) affects an individual's likelihood of accepting a similar habitat or host during dispersal (Immelmann
1975; Davis and Stamps 2004). Because this effect can produce intra-population variation in habitat and host choices, it has long held the interest of entomologists interested in the formation of host races (Walsh 1864; Hopkins 1917), ethologists interested in behavioral development (Thorpe and Jones

*Present address: Department of Biology, Vassar College, Poughkeepsie, New York 12604-0731 USA

The Quarterly Review of Biology, December 2008, Vol. 83, No. 4

Copyright (c) 2008 by The University of Chicago. All rights reserved.

0033-5770/2008/8304-0002\$15.00 
1937; Immelmann 1975), and evolutionary biologists interested in the maintenance of genetic variation (Hedrick et al. 1976; Taylor 1976; Hedrick 1990) and sympatric speciation (Maynard Smith 1966; Beltman et al. 2004). Furthermore, such effects hold implications for conservation efforts (Stamps and Swaisgood 2007) and pest management (Solarz and Newman 2001; McCall and Kelly 2002; Rietdorf and Steidle 2002; Gandolfi et al. 2003).

Although scientists recognize that the influence of natal experience on habitat and host selection has many potential consequences, empirical studies on this effect yield widely variable results, thus leaving its actual ecological importance unclear (Van Emden et al. 1996; Barron 2001). In a previous paper, I demonstrated that statistically significant natal experience effects have been observed across a broad taxonomic range of species (Davis and Stamps 2004). However, researchers studying different taxonomic groups have different views about the importance of these effects. Building upon Thorpe's (1937; 1938; 1939) research, scientists have used parasitoid wasps to explore the role of learning in effective biological control (Turlings et al. 1989; Gandolfi et al. 2003). Meanwhile, butterfly ecologists often assume that experience prior to adult dispersal need not be considered a source of host choice variation (e.g., Hanski and Singer 2001; Forister 2004; but see Bossart and Scriber 1999), as early studies on butterflies demonstrated no effect of the larval host on the oviposition decisions of adults (Wiklund 1974; Tabashnik et al. 1981).

My goal in this review is to describe patterns of variation seen in published results on natal experience effects and to explore the extent to which this variation may be due to methodological differences between studies, the nature of the taxonomic groups studied, or species-level differences in the adaptive value of responding to natal experience. First, I will explain the methods that I used to compile data on natal experience effects, and I will discuss the general patterns I observed. I will then describe the mechanisms by which the na- tal habitat can influence the choices of dispersing animals and test hypotheses about how experimental designs differ in their ability to detect the effects of each of these mechanisms. Finally, I will review and test adaptive hypotheses introduced in previous papers (Stamps and Davis 2006; Davis 2007) about why natal experience affects habitat preferences and which species should be most influenced by this type of experience. My hope is that this synthesis will assist researchers as they develop hypotheses about when and in which species natal experience effects are likely to be observed, design experiments by which to test those hypotheses, and predict how natal experience effects may influence the evolution and ecology of different species.

\section{Reviewing the Literature}

\section{DATA COLLECTION}

The studies discussed in this review are drawn from the most exhaustive literature search to date for studies on the effect of natal experience on habitat choice. Data were collected by searching ISI Web of Science with keywords including "experience and preference," "experience and choice," "preference induction," "habitat imprinting," "Hopkins's host selection principle," and "pre-imaginal conditioning." In order to gather the greatest amount of data possible, I collected additional papers that were not found in the web search but that were cited by studies contained therein. This final step may have created some bias, but it is my impression that because many of the papers were written in the context of the debate about whether or not natal experience plays a role in shaping habitat preferences, authors frequently cited papers both with and without statistically significant effects of natal experience.

A typical test for the effect of natal experience on habitat choice involves dividing subadult subjects (e.g., eggs, larvae, or pupae in insect studies, nestlings or fledglings in bird studies) into treatment groups that will develop in different habitats or hosts. When the subjects reach dispersal age, behaviors associated with habitat or host choice are tested. Experiments in the 
studies I surveyed varied in their specific methods, and in order to be included in the accompanying tables (available online at The Quarterly Review of Biology homepage, www.journals.uchicago.edu/QRB) and analysis, four methodological criteria needed to be met:

1. Natal experience: The study had to specifically explore the effect of predispersal experience. The processes that allow postdispersal experiences to influence habitat choice may also occur in the natal habitat, but it is possible that the effect of experience in the natal habitat is unique in magnitude and/or direction. Therefore, experience treatments had to be provided to subjects at a life stage during which, if in the wild, they would still be in the habitat in which their parents placed them (i.e., in their natal habitat). For example, although much insight has been gained through experiments on early experience in Drosophila, many of these studies were excluded from my analysis because the subjects were provided with experience for three or more days after adults emerged from pupae (e.g., Jaenike 1982; Hoffmann and Turelli 1985; Taylor 1986; Cadieu et al. 1999), thus conflicting with some observations that suggest that they leave their natal fruit within 24 hours of emergence (Hoffmann 1988).

2. Genetic differences controlled: The study had to control for genetic differences that might have contributed to differences in habitat and host choice. Several field studies that indicated that natal experience plays a role in the habitat choice and dispersal patterns of mammal subpopulations were excluded because of the possibility that genetic differences were responsible for the observed differences in habitat choice (e.g., Haughland and Larsen 2004a,b; Sacks et al. 2004; Mabry and Stamps 2008). Similarly, studies in which animals were reared for several generations in alternate habitat types before choice was tested were excluded, as it is possible that these treatments resulted in selection for preferences. One exception that is included in the table of studies (Table 1, available online at The Quarterly Review of Biology homepage, www.journals.uchicago .edu/QRB) is a study on aphids by Lushai et al. (1997). I included this study in the table because the clonal lines of aphids that were reared for multiple generations on different host plants were unlikely to respond to selection. However, I excluded the results from analysis, because differences in behavior could have accumulated as a result of maternal effects.

3. Postdispersal choice: The habitat choice of subjects must have been tested at an age during which the animal is likely to disperse from its natal habitat in the wild. At this age, the choices individuals make will usually determine the habitat or hosts in which their offspring develop. Thus, classic studies on visual and olfactory "imprinting" in frog tadpoles (Wiens 1970; Hepper and Waldman 1992) were excluded from my analysis. Similarly, studies on how larval preferences are influenced by earlier larval experience were also not included. Finally, for eusocial insects, I only considered reproductives capable of dispersal, and, although there are a number of studies demonstrating a strong effect of early experience on nest choice in ants (Jaisson 1980; Dejean 1990; Djieto-Lordon and Dejean 1999a,b), these were only included when the choices of winged females rather than workers were tested.

4. Habitat or host choice: Experiments had to test habitat or host choice. This specifically excludes experiments on food choice (e.g., Burghardt and Hess 1966; Phillips 1977; Cassidy 1978; Provenza and Balph 1988; Desbuquois and Daguzan 1995; Vargas and Anderson 1996) but includes all cases where the animal's choice will likely affect its mate choice or where its offspring will develop. When results for male and female choices were presented separately, for simplicity, I only used the results from females.

\section{EFFECT SIZE CALCULATIONS}

Standardized effect sizes of natal experience on habitat choice were calculated from data provided in the text, tables, and graphs of the collected studies. When data were only available in graphical form, I used the free-ware program Data Thief III, version 1.0 (www.datathief.org), to collect quantitative measures of response. Experi- 
mental results were reported as means and standard deviations, or as proportions. In order to include both types of data in the analysis, I calculated correlation coefficients using the equations provided in Rosenberg et al. (2000). Because the sampling distribution of correlation coefficients is non-normal, I converted coefficients to the normally distributed Fisher's $z$ for analysis.

I also recorded whether or not the observed effect was statistically significant. Several studies did not make the appropriate statistical comparisons. In these situations, I used available data to directly compare the responses of each treatment group (using t-tests or chi-square tests), and I then determined whether the effect of the natal experience treatment was statistically significant. In some cases, not enough information was provided for me to calculate effect sizes or statistical significance without risking the use of pseudo-replicated data (Hovanitz 1969; Kaur et al. 2003). These studies are included in the tables of studies (Tables 1 and 2) but were not used in analyses.

Habitat choices were tested with either one- or no-choice tests, in which dispersers are presented with a single habitat or cue, or with two- or multiple-choice tests, in which subjects choose between two or more habitats. Two-choice experiments are largely influenced by the subject's relative attraction to the offered habitats (i.e., its preference). One-choice tests, however, are influenced both by the subject's preferences and by its selectivity or choosiness (Singer et al. 1992; Stamps and Davis 2006; Davis 2007). Because these two types of experiments potentially measure different components of habitat choice behavior, their results were analyzed and presented separately.

Multiple-choice tests of habitat choice: Choices made in multiple-choice tests were assumed to reflect the subjects' preferences from among the offered habitats. Data were available for 155 multiple-choice tests from 61 articles on 66 species. I was able to calculate Fisher's $z$ values for 130 tests. Most experiments offered only two habitat types at a time. When subjects were offered more than two choices, I either re-categorized the multiple choices into two choices (e.g., by regrouping four humidity levels into two levels-high and low [Steidle and Reinhard 2003]), or I removed less ecologically relevant choices from consideration (e.g., by using the preference scores for pine vs. leafy perches when pine, leafy, and plastic perches were offered as choices [Glück 1984]).

For two-choice studies, I calculated a "rate difference" effect size, $\Delta e$, in addition to $z$ values, thus allowing for easy interpretation of preference results. In this context, $\Delta e=p_{x \mid x}-p_{x y y}$, where $x$ and $y$ are the offered habitats and $p_{x y y}$ is the proportion of individuals selecting habitat $\mathrm{x}$, the mean proportion of time spent near habitat $\mathrm{x}$, or the mean proportion of eggs laid in habitat $\mathrm{x}$, when the subjects have natal experience with habitat y (Turelli et al. 1984). The standard errors of $\Delta e$ were calculated using the standard deviations of $p_{x \mid x}$ and $p_{x \mid y}$ (Turelli et al. 1984; Rosenberg et al. 2000).

One-choice tests of habitat choice: I collected data from 94 one-choice experiments, documented in 22 articles on 20 species. The studies discussed in a large majority of these articles (17) were conducted on parasitoid wasps. One-choice tests are conducted with a variety of response variables; therefore, only Fisher's $z$ values were useful for quantifying the comparative effect of the natal habitat on later habitat choice (Rosenberg et al. 2000). The raw response values and their units of measurement are provided in Table 2 (available online at The Quarterly Review of Biology homepage, www.journals.uchicago .edu/QRB) to illustrate the context of each experiment.

When interpreting the results of onechoice tests, the effect of experience treatments on an individual's activity level and/or on the likelihood that the individual will approach a cue (i.e., the individual's overall responsiveness) must be considered. For example, a study on the parasitoid wasp Diaeretiella rapa demonstrated that wasps reared in collard green-reared hosts were more responsive to collard odors than wasps reared in potato-reared hosts (Sheehan and Shelton 1989), thus suggesting an effect of natal experience on preference. However, the col- 
lard treatment wasps also responded more strongly to potato cues. Therefore, most of the effect that natal experience had on the wasps' response to collard green odor can be explained by an increased overall responsiveness to general plant cues. This may reflect differences in selectivity, which would potentially affect the choices that the wasps would make in the wild (Stamps et al. 2005). However, it may also reflect differences in the length of a refractory period (Stamps et al. 2007) during which individuals will not accept any habitat. Differences in the lengths of refractory periods will not necessarily influence the types of habitats that animals choose in the wild. Therefore, when possible, the effect of natal experience on habitat choice is best measured as the strength of the statistical interaction between the natal experience and the habitat offered.

Because of the potential for increased overall responsiveness and increased responsiveness to the natal habitat to be confounded, two forms of Fisher's $z$ were calculated from one-choice data. The first effect size, $z_{m}$, reflects the strength of the main effect of natal experience on responsiveness to a single habitat or cue and generally does not control for the possible effect of natal experience on increased overall responsiveness to general host or habitat cues. I calculated $z_{m}$ scores from t- or chi-square statistics representing the effect of experience on the response to a given habitat. The index, $z_{m}$, was calculated for 90 of the experiments.

The second index, $z_{i}$, is the effect size of the interaction between the natal habitat and the habitat or cue offered. Thus, values of $z_{i}$ will be largest when individuals show a strong response when presented with natal habitat cues, but a weak response when presented with other habitat cues. For studies that used proportional data, I conducted a logit-loglinear analysis, with the proportion of subjects responding to cues as the dependent variable and natal experience and the cue offered as independent variables. The normal deviation of the parameter estimate for the interaction between experience and cue offered was first converted to a correlation coefficient and then converted to a $z_{i}$ score. For studies that used continuous response variables, I used the means and standard deviations to calculate, using an ANOVA, the $F$-value for the interaction between experience and cue offered. The $F$-value was converted to a correlation coefficient, $r$, and then to a Fisher's z-score (Rosenberg et al. 2000). I was only able to calculate $z_{i}$ scores for 16 studies.

\section{ANALYSIS OF EFFECT SIZES}

Using Fisher's $z$ as the effect size and $1 /(N-3)$ (where $N$ is the total sample size for the experiment) as the sampling variance, I calculated the cumulative effect size and heterogeneity statistics and, using MetaWin 2.0 (Rosenberg et al. 2000), tested for the role of several methodological variables using fixed effect models. When testing predictions about taxonomic differences, I calculated the cumulative effect size for each species by averaging the scores for each experiment on that species, weighted by the reciprocal of the sampling variance for that experiment (Rosenberg et al. 2000). These cumulative effect sizes (hereafter, "species means") were treated as estimates of the true effect size for each species and were analyzed with parametric statistics (SPSS 15.0).

As with any literature review, the magnitude of an effect may be slightly biased upwards as a consequence of the "filedrawer effect," in which nonsignificant results are left unpublished (Gurevitch and Hedges 1999). For example, the data presented on Papilio polyxenes were left unpublished for nearly 20 years before they were paired with another study on host choice that demonstrated a statistically significant effect (Heinz and Feeny 2005). A negative correlation between effect size and the sample size of the experiment indicates that experiments with small sample sizes are only published if they reveal large effect sizes (Begg and Mazumdar 1994). Among multiple-choice experiments, I found a small negative correlation between these values $\left(r_{S}=-0.20, p=0.02\right)$. However, I also calculated Rosenthal's fail safe number (Rosenberg et al. 2000) - an estimate of the number of nonsignificant studies that 
would need to be sitting in file drawers in order to change the generally positive effects of natal experience observed here to nonsignificance. This number is estimated to be 18,004 . Rosenthal's fail safe number is usually tested against the critical value $5 k$ +10 , where $k$ equals the number of studies currently in the meta-analysis (Rosenthal 1979). The critical value for this study is, thus, 660. Therefore, while the cumulative effect sizes reported here may be slightly inflated, the general pattern of increased response to natal experience is not due to publication bias.

Publication bias among one-choice tests appears to be a larger problem than in multiple-choice tests. There is a relatively strong negative correlation between the $z_{m}$ effect size and sample size $\left(r_{S}=-0.45, p<0.0001\right.$; Rosenthal's fail safe $=9682$, critical value $=$ 460). On the other hand, among studies for which $z_{i}$ could be calculated, there is no correlation between the $z_{i}$ effect size and sample size $\left(r_{S}=0.02, p=0.93\right.$; Rosenthal's fail safe $>10^{9}$, critical value $\left.=90\right)$.

\section{GENERAL PATTERNS}

\section{Multiple-Choice Tests}

Table 1 presents the results from multiplechoice studies on 66 species. The cumulative effect size across all experiments for which $z$ scores could be calculated is 0.26 $(95 \% C I=0.24-0.29, k=130)$. This corresponds to a correlation coefficient of 0.26 , implying that, on average, natal experience treatments have only a weak effect on preference. However, there is a great deal of heterogeneity among studies in the size of the effect $\left(Q_{T}=586.46, d f=125, p\right.$ $<0.0001)$. Furthermore, the average species mean effect size, which weights the effects observed in each species equally, is slightly larger $(z=0.35, C I=0.35-0.55, r=$ $0.33)$. This difference is most likely due to the fact that when species were studied multiple times, a subset of experiments was designed to exclude the mechanisms that allow natal experience to affect choices (Table 1).

Most multiple-choice studies were conducted using birds or insects. The mean $z$

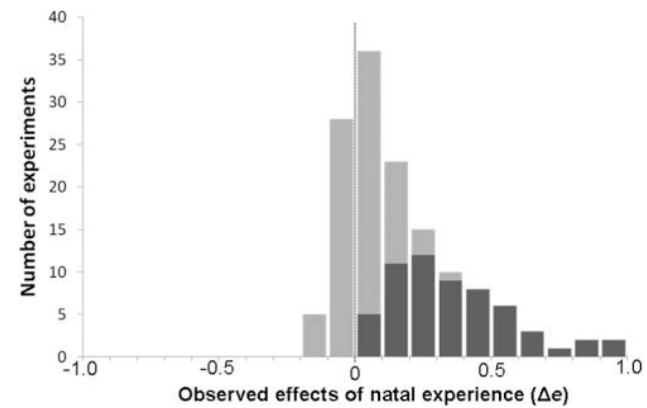

Figure 1. Distribution of the Magnitude of Natal Experience Effects on Habitat CHOICE

Histogram of observed values of $\Delta e$, illustrating the proportion of individuals choosing habitat $\mathrm{x}$ over $\mathrm{y}$ when reared in $\mathrm{x}$ minus the proportion of individuals choosing habitat $\mathrm{x}$ over $\mathrm{y}$ when reared in $\mathrm{y}$, based on the results of multiple-choice tests of the effect of natal experience on habitat choice. Dark gray bars represent statistically significant effects of experience. Light gray bars represent effect sizes not significantly different from 0 .

for bird species is 0.52 , while the mean $z$ for insects is 0.28 (Figure 1 ). This difference is marginally significant $(t=1.96$, $d f=46, p=0.054)$. Because most studies conducted with birds have small sample sizes and, therefore, are less likely to be published when effect sizes are small, this taxonomic difference could be due to publication bias. However, among studies on birds, there is no evidence of additional publication bias (correlation between sample size and effect size: $r_{S}=-0.16, p=$ $0.56)$. This taxonomic difference is therefore more likely due to either real differences between insects and birds in the importance of natal experience on habitat preference or methodological differences in the way they are tested, as I will discuss below.

I also compared the effect sizes seen in different insect orders. Surprisingly, there was little difference among the most commonly studied insect orders (average species means: Lepidoptera: 0.21, Diptera: 0.32, Hymenoptera: $0.18 ; F=0.605, d f=2.28, p=$ $0.55)$. The view among lepidopterists that natal experience does not affect host choice may be specifically derived from studies on 
butterflies that demonstrate a significantly smaller effect of natal experience than that in moths (butterfly species means: 0.08, moth species mean: $0.31 ; F=4.76, d f=1.10$, $p=0.05)$. This difference, however, may also result from methodological effects.

\section{One-Choice Tests}

The mean $z_{m}$ across all experiments is $0.20(C I=0.17-0.23)$, and the mean $z_{i}$ is $0.21(C I=0.14-0.27)$. Thus, the magnitude of the observed effect in one-choice tests appears to be smaller than in multiplechoice tests. Once again, there is a great deal of heterogeneity among effect sizes $\left(z_{m}: Q_{T}=851.24, d f=88, p<0.0001 ; z_{i}: Q_{T}\right.$ $=38.08, d f=16, p=0.0015)$. The average species mean $z_{m}$ is $0.32(C I=0.15-0.49)$, and the average species mean $z_{i}$ is 0.17 $(C I=0.06-0.28)$. There are not enough nonparasitoid studies conducted with onechoice tests for a comparison of taxonomic groups.

\section{SUMMARY OF RESULTS}

In both one- and multiple-choice tests, the mean effect of natal experience is a slight but significant increase in acceptance of the natal habitat. In both types of experiments, there is a great deal of heterogeneity among effect sizes. Some of this variation may be due to methodological differences among studies, as I will discuss in the following section. Furthermore, the median effect sizes in both types of tests are smaller than the mean effect sizes (multiple-choice average species mean $=$ 0.35 , median species mean $=0.27$; onechoice average species mean $=0.32$, median species mean $=0.18$ ). Thus, the distribution of effect sizes is skewed to the right (Figure 2), indicating that, despite the small effect it may have on the habitat choices of most species, much of the individual variation in choice among other species is in fact due to natal experience (e.g., Payne et al. 2000). In the third section of this review, I will discuss some of the adaptive hypotheses for why experience tends to increase preferences for natal cues, and why the magnitude of this effect is very

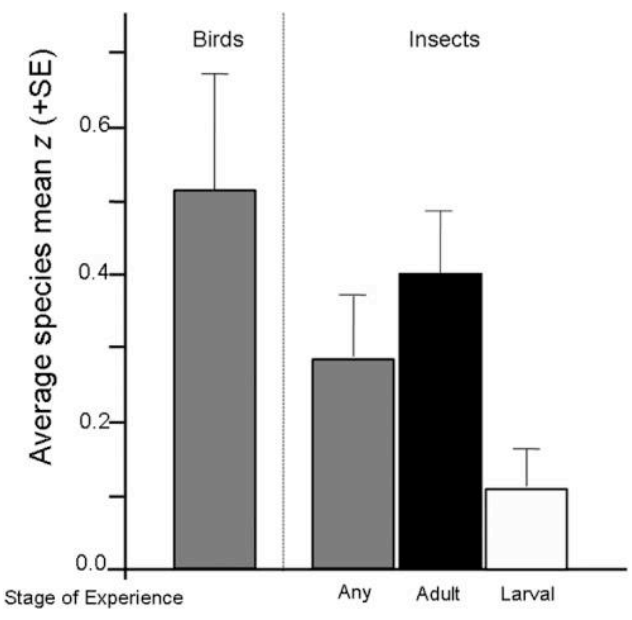

Figure 2. Average Effect Sizes Observed in EXPERIMENTS ON THE EFFECT OF NATAL Experience on Habitat Choice in Bird ANd Insect SPEcies

Effect sizes were calculated using Fisher's $z$ analysis. Values were determined by calculating a weighted mean $z$ for each species (weight $=1$ /sampling variance) and by averaging across species. In insect studies, species means were calculated for all studies (gray bar), for studies in which experience was provided after emergence from the pupa (black bar), and for studies in which experience was limited to the larval phase (white bar). Bars represent standard errors.

large for some species but small in most others.

\section{How Natal Experience Influences Habitat and Host Choice}

The most commonly discussed mechanism by which natal experience influences habitat choice is a learned increase in preference for cues experienced in the natal habitat. However, a thorough review of the literature reveals at least three distinct mechanisms by which experience in the natal habitat can influence the choices animals make during dispersal. In this section, I will review these three mechanisms and discuss how the specific methods used to conduct studies, such as how and when animals are exposed to natal habitats and how choices are measured, can determine whether a particular mechanism can affect the choices of experimental subjects. 
SELECTIVITY IN ONE-CHOICE TESTS

Animals in poor physiological condition and/or under tighter time constraints are generally less selective when choosing resources or mates (e.g., Thomas et al. 1998; Moore and Moore 2001; Barton Browne and Withers 2002; Baker 2004). Thus, a potentially common mechanism by which natal habitat can influence later habitat choice is by influencing the physiological condition of dispersers (Stamps and Davis 2006). Individuals dispersing from low-quality habitats may often be in poor physiological condition and, in turn, less selective (i.e., more willing to accept similarly low-quality habitats) than individuals from high-quality habitats. Three one-choice studies presented in Table 2 (available online at The Quarterly Review of Biology homepage, www.journals.uchicago.edu/QRB) describe the effect of the natal host on the subject's condition (size or starvation resistance) (Bjorksten and Hoffmann 1998b; Vos and Vet 2004; Davis 2007). In all three of these studies, individuals reared in hosts or habitats that left them in poor condition demonstrated reduced selectivity.

In multiple-choice tests, individuals should typically select the more preferred of the offered habitats, thus masking any differences in selectivity between treatment groups. Therefore, this mechanism will play a larger role when subjects are tested in one-choice tests. Furthermore, the degree to which experience treatments influence the physiological condition of subjects should affect the extent to which individuals from different treatments differ in their selectivity.

\section{PLASTICITY AND HABITAT-SPECIFIC PERFORMANCE}

Experience in the natal habitat can result in the development of traits well-suited to life in the natal habitat type, but poorly suited to non-natal habitats. When this occurs, individuals may have positive experiences in their natal habitat type and less positive experiences in non-natal habitats. Consequently, individuals may ultimately settle in habitats most similar to their natal habitat, regardless of what their preferences might have been upon dispersal. For example, the size of the parasitoid wasp Pachycrepoideus vindemiae is strongly influenced by the size of the host (a fly pupa) in which it developed as a larva. As a result, individuals reared on large pupae (Musca domestica) are better at handling large pupae during oviposition than they are at handling small pupae (Drosophila melanogaster), and vice versa (Morris and Fellowes 2002). The experience of emerging from a Musca pupa does not immediately increase the wasp's attraction to Musca pupae (Table 1, available online at The Quarterly Review of Biology homepage, www.journals .uchicago.edu/QRB). Instead, because of their increased efficiency at attacking large pupae, after a single experience ovipositing in Musca, large wasps become more likely to attack that species again. On the other hand, small wasps, such as those reared on Drosophila pupae, do not become more likely to attack Musca after oviposition experience with that species. The direct influence of plastic traits on how individuals assess different habitats or hosts is rarely discussed, but it may be a common mechanism by which natal experience affects habitat choice.

This mechanism will only be observed if phenotypic differences can develop between treatment groups. For instance, feeding on a plant may trigger an up-regulation of detoxifying secondary compounds (Ortega-Reyes and Provenza 1993; Akhtar and Isman 2003), such that subjects become more likely to use a habitat where a normally toxic plant is a major food source. The increased use of this habitat might not be observed if subjects are exposed to the plant's odor but not allowed to ingest the plant.

In order for this mechanism to function, the subject must also be able to obtain feedback about how its phenotype performs. For example, the anemonefish $\mathrm{Am}$ phriprion ocellaris is innately attracted to the odors of its anemone host, Heteractis magnifica, and natal experience with that host causes only a slight increase in attraction to those odors. However, when measuring time spent in proximity to an actual host anemone rather than just its odor, fish with natal experience on that host spend much 
more time in proximity to it than fish without prior experience with anemones (Arvedlund and Nielsen 1996). In addition to increased attraction to odors, a potential mechanism for this pattern is that natal experience with a particular host improves the ability of fish to quickly acclimate to the nematocysts of the anemone (Arvedlund and Nielsen 1996; Arvedlund et al. 1999). The effect sizes seen in the literature search were affected by whether or not individuals were able to interact with the offered habitats $\left(z_{\text {contac }}\right.$ $=0.29, z_{\text {without contact }}=0.24 ; Q=4.82, d f=1, p=$ 0.028 ). However, such a pattern would also arise if contact were required for animals to detect cues that they prefer as a consequence of learning in the natal habitat.

\section{LEARNING NATAL CUES}

While the examples provided above indicate that natal experience can influence habitat choice through nonlearning mechanisms, learning of natal cues clearly plays an important role in the development of preferences for the natal habitat as well. Several learning mechanisms can occur in the natal habitat, including imprinting, associative learning, and habituation (Hershberger and Smith 1967; Manning 1967; Bernays and Weiss 1996). The ability to detect the effect of learning is influenced by whether or not the experiment provides an opportunity for learning, and also if any learned preferences are stored in memory until choices are tested.

Associative learning will only be observed in experiments when an innately attractive cue (the unconditioned stimulus) is present in association with the natal habitat cue for which preference is being tested (the conditioned stimulus). For example, the parasitoid wasp Trichogramma $\mathrm{nr}$ brassicae, which lays its eggs in moth eggs, demonstrates increased attraction to tomato plants when it is allowed to emerge from its host in the presence of these plants. However, if the wasp is separated from its host prior to emerging as an adult, exposure to tomato plants no longer increases attraction to them. The wasp's increased attraction to its natal host plant is due to an association of host plant cues with an innately attractive host stimulus (Bjorksten and Hoffmann 1998a). A similar pattern is seen in Kester and Barbosa's (1991) study on Cotesia congregata; attraction to cherry volatiles is larger when first experienced in association with the host. If natal experience treatments are not designed to be biologically realistic, subjects may not experience an unconditioned stimulus in the natal habitat, thus reducing any effects on preference.

In order to affect choices made during dispersal, preferences learned in the natal habitat must be held in memory. In holometabolous insects, the nervous system is reorganized during metamorphosis (Armstrong et al. 1998; Ray 1999; Tissot and Stocker 2000), making it unlikely that behaviors learned during the larval stage are retained in adulthood. Therefore, in insect studies, a potentially important source of variation in the reported strength of natal experience on the preferences of dispersing adults is whether or not researchers tested for the effect of larval or adult experience. Nine two-choice studies tested the effects of both larval and adult experience. Among these, the effect of larval experience alone was always smaller than when the subject was provided experience at emergence (Binomial test, $p=0.002$ ). Across all multiple-choice experiments on holometabolous insects, the stage at which experience was provided explained a significant proportion of heterogeneity $\left(z_{\text {adult }}=0.28, z_{\text {laval }}=0.19 ; Q=9.51, d f=\right.$ $1, p<0.01)$.

The inclusion of experiments that only allow subjects larval experience may depress the mean effect size of natal experience reported for insects. After excluding studies that only allowed larval experience and recalculating species mean effect sizes accordingly, birds still showed stronger effects of natal experience than insects, but this effect was no longer significant (birds: $z=0.52$, insects: $z=0.37 ; t=1.125, d f=$ $34, p=0.26$ ) (Figure 1). Similarly, the difference in the mean effect sizes of butterflies and moths may be partially explained by the fact that most studies on butterflies only provided subjects with larval experience prior to testing preference, 
whereas in most moth studies, adult experience was also provided (Table 1 ). However, it is important to note that the differences in methodology between the moth and butterfly studies, as well as between bird and insect studies in general, may reflect differences in the species' natural histories. Specifically, while many of the moth species studied are pests of stored grain or agricultural fields and are, therefore, likely to encounter their natal habitat upon emergence from their cocoons, many of the studied butterfly species move some distance away from their natal habitat prior to undergoing metamorphosis.

Interestingly, in one-choice studies on insects, the mean effect size of experience on the response to a given habitat $\left(z_{m}\right)$ is only slightly smaller when natal experience is provided during the larval life stage rather than the adult life stage $\left(z_{m \text { (larval })}=\right.$ $0.17 ; z_{m(\text { adult })}=0.20 ; Q=1.079, d f=1, p=$ $0.30)$. Indeed, in the three one-choice studies that directly compared the effect of both larval and adult experience, the main effect on responsiveness to habitat cues $\left(z_{m}\right)$ is larger when experience is larval (Hérard et al. 1988; Sheehan and Shelton 1989; Gandolfi 2003). It may be that although larval experience typically has little effect on learned preferences for natal cues, it influences disperser choices by affecting their physiological condition; that is, individuals reared as larvae in high-quality habitats can better afford to be selective. The strength of the interaction between natal habitat and habitat offered in one-choice tests $\left(z_{i}\right)$ is affected by the stage at which experience was provided $\left(z_{i(\text { adult })}=0.30 ; z_{i(\text { larval })}=0.18 ; Q=4.12, d f=1\right.$, $p=0.045)$. This is a further indication that while the interaction between natal habitat and habitat offered $\left(z_{i}\right)$ provides a good measure of the effect of natal experience on relative attraction to different habitats, the main effect of natal experience on acceptance of a given habitat $\left(z_{m}\right)$ can be the consequence of increased responsiveness to general habitat cues.

\section{CONCLUSIONS}

At least three mechanisms allow natal experience to influence the habitat choices of dispersers, and these mechanisms must be kept in mind when designing experiments. If one is interested in estimating the overall effect of natal experience on habitat or host choices in the field, experiments should be conducted with one-choice tests to detect condition-dependent changes in selectivity and should allow the animal to directly interact with the offered choice, in order to detect phenotype-dependent differences in the ability to utilize natal and non-natal habitats. On the other hand, if one is specifically interested in testing the degree to which learning in the natal habitat influences habitat choice, two-choice tests on animals that are unlikely to differ in nonbehavioral traits may be more appropriate.

\section{Adaptive Variation in Preference FOR the Natal Habitat}

One clear pattern emerging from the data presented in Table 1 and Figure 2 is that there is a great deal of interspecific variation in the degree to which animals prefer their natal habitat. Although some of this variation is due to differences in experimental methods, it might also reflect genetic differences that have evolved as a consequence of differences in the costs and benefits of an increased preference for the natal habitat. In this final section of my review, rather than focusing on selectivity, I will instead focus my discussion on the preference for the natal habitat type at dispersal. I will review two hypotheses for the fitness benefits of an increased preference for the natal habitat and discuss why these benefits might be larger for some species than others. I will also use available data to test two basic predictions of the hypotheses: a) that the effect of natal experience on preferences is adaptive, and b) that species differences in reported effect sizes reflect adaptive differences in their response to natal experience.

\section{PLASTIGITY IMPROVES THE QUALITY OF THE NATAL HABITAT}

Selection often shapes plastic traits, causing animals to become better adapted to the habitat in which they develop (Gotthard and Nylin 1995), which, in turn, re- 
sults in habitat-specific phenotypic variation within populations. When this occurs, individuals reared in a particular habitat will exhibit higher fitness in that habitat than individuals from other habitats, and selection should, therefore, favor an increase in preference for the natal habitat. Such a preference would be adaptive, as it would reduce the costs associated with sampling multiple habitats to determine how well an individual's phenotype "fits" with a given habitat (Davis and Stamps 2004).

In this context, the strength of preference for the natal habitat should depend on the fitness consequences of choosing a non-natal habitat. For instance, if an animal can undergo further phenotypic changes if it settles in a non-natal habitat type, selection to prefer the natal habitat should be weak. Similarly, assuming that such environmentally-induced traits cannot be passed on to offspring, selection will favor individuals with an increased preference for the natal habitat only if they will be living in that habitat. Thus, one might predict that oviposition choices are less influenced by natal experience than by habitat choices in general. However, comparing experiments that tested egg-laying decisions with experiments that tested other choices (Table 1, available online at The Quarterly Review of Biology homepage, www .journals.uchicago.edu/QRB), there is no evidence of such a difference $(Q=1.121$, $d f=125, p=0.29)$. One reason for this lack of difference is that experience in the natal habitat can specifically improve performance in traits important for oviposition (Morris and Fellowes 2002). Another reason is that environmentally-induced performance in a given habitat can indeed be passed to offspring via maternal effects (e.g., Akhtar and Isman 2003).

\section{SURVIVAL AS AN INDICATOR OF HABITAT QUALITY}

The true "quality" of a given habitat is not fixed; environmental variation in the components that make up the habitat can, in turn, cause variation in the habitat's quality. When this is the case, the fact that an individual has survived to dispersal age can provide some indication of the current quality of its natal habitat. For example, imagine two fields containing several host plants of a hypothetical herbivore. In field 1 , predators are very common on host plant A, such that only $10 \%$ of individual herbivores survive to dispersal age on that plant, but, in field 2, predators are nearly absent on host plant A, such that $100 \%$ survive to dispersal age. All else being equal, an individual that survives to dispersal age on host plant $\mathrm{A}$ is ten times more likely to be in field 2 than in field 1 -i.e., in an environment in which host plant A is a suitable, predator-free host. Thus, if mean dispersal distance in this herbivore is short enough to enable it to remain in its natal field, selection will favor genotypes that increase acceptance of host plant A (the natal habitat from which the herbivore emerged).

Similar information can be gained from the natal habitat when there is genetic variation in how well-suited individuals are to different habitats. For example, in brood parasitic birds, such as cuckoos, the appearance of eggs and/or nestlings varies among subpopulations (gentes) but must closely mimic the appearance of those of the host species, or else the host species will reject the parasite and/or abandon the nest (Antonov et al. 2006). If the brood parasite reaches fledgling age, its genotype must be good at mimicking its natal host species (Teuschl et al. 1998; Honza et al. 2001). Although the role of natal experience in shaping host preference in cuckoos is not clear (Brooke and Davies 1991; Teuschl et al. 1998; Vogl et al. 2002), this may help explain why natal experience plays such a strong role in host choice in other brood parasites, such as indigobirds (Sorenson et al. 2003).

Selection favoring a preference for the natal habitat should be greatest when there are large mortality differences between environments or among genotypes. Returning to the example of host plant A and the hypothetical herbivore, imagine that, in field 1, host plant A contains a resistance gene that reduces fecundity in herbivores, 
while, in field 2, host plant A is a nonresistant wild type. While all individuals might survive to adulthood in both fields, there are clear differences in herbivore fitness. In this situation, mere survival to adulthood provides no indication as to whether host plant A is high-quality in the immediate environment, therefore selection for increased preference for the natal habitat should be weak. The strength of selection also depends on the degree to which the environment changes across space and time, as well as on species characteristics such as the distance traveled after dispersal during the search for habitat. If our hypothetical herbivore has a dispersal distance that routinely takes it between fields, a preference for the natal habitat would not be adaptive.

\section{TESTING PREDICTIONS}

Based on these adaptive hypotheses for why natal experience might affect habitat preferences, two testable predictions can be made with the data in Table 1. First, both adaptive hypotheses predict an increased preference for the natal habitat. The data compiled in this literature search indicate that the effect of experience on preference for the natal habitat is almost universally positive. The observed effects of natal experience are only negative in 20 of the 130 experiments presented in Table 1 (also see Figure 2), and the negative effect of natal experience is not statistically significant in any of those studies (Table 1). It is unlikely that this trend is simply due to constraint, as the opposite pattern (negative preference induction) has been observed in other ecological contexts. For example, generalist foragers, such as grasshoppers and hermit crabs, tend to avoid recently encountered foods (Bernays and Bright 1993; Thacker 1996), perhaps in order to get a balanced diet. Second, both hypotheses assert that if there is little variation across space and time in the relative quality of each habitat, natal experience will have little effect on habitat preference. When individuals in a population are physiologically or morphologically specialized to use a particular habitat, the relative quality of that habitat is always best. The habitat preferences of extreme specialists should, therefore, be less influenced by natal experience than those of generalists (Rozin 1976).

The idea that generalists should be more strongly influenced by natal experience than specialists has been explicitly tested with birds and salamanders (Mushinsky 1976; Slagsvold and Wiebe 2007). Mushinky (1976) demonstrated that while the green salamander Aneidus aeneus (a species morphologically specialized for life in the crevices of rock outcroppings) has a consistently strong preference for substrate that resembles its natural habitat, the substrate preferences of the habitat generalist dusky salamander Desmognathus ochrophaeus depend on the substrate on which it is reared as a juvenile (Table 1). Similarly, the habitat preferences of the morphologically specialized blue tit (Cyanistes caeruleus) are not influenced by cross-fostering with great tits (Parus major), while the more generalist great tits demonstrate a shift in habitat preference when cross-fostered with blue tits (Slagsvold and Wiebe 2007) (Table 1).

The only additional set of studies that is suitable for comparison is on Papilio butterflies. Bossart and Scriber (1999) point out that $P$. glaucus is the most generalist Papilio species, breeding on tree species from several taxonomic families, and it is also the only species in which preference has been shown to be affected by larval experience (Bossart and Scriber 1999). However, studies on P. machaon (Wiklund 1974) and P. polyxenes (Heinz and Feeny 2005), two specialists reared on members of the parsley family (Apiaceae), demonstrated no effects of natal experience. More research is necessary on the relative sensitivity of specialist vs. generalist species to experience, but this preliminary analysis suggests that such comparisons may be promising.

\section{Conclusions}

In this paper, I have demonstrated that when natal experience influences habitat choice, it almost always increases an individual's likelihood of choosing the natal habitat type. Although the effect of natal experience is generally small, it appears 
responsible, in a few cases, for much of the variation observed in habitat choice. More importantly, this study demonstrates that some of the variation observed in empirical studies is due to methodology used by researchers and, potentially, to differences in the ecology of the species tested.

Recent interest in the effect of natal experience on habitat preference has been largely driven by the possibility that such a mechanism can facilitate sympatric speciation (Maynard Smith 1966; Beltman et al. 2004; Beltman and Haccou 2005). However, the data provided in this review indicate that, in most species, the effect of natal experience on habitat preference is not strong enough, in fact, to play a large role in sympatric speciation. On the other hand, it is clear that the habitat preferences of some species are largely dependent on natal experience. If a strong preference for the natal habitat can indeed facilitate sympatric speciation, then the predisposition to such evolutionary processes is heterogeneous among species. The data presented here indicate that, all else being equal, a preference for the natal habitat is more likely to have evolutionary implications for birds and for generalist species than for insects or specialists.

The variation in the effects of natal experience observed in this study holds several applied implications. For example, the choice of biological control agents may depend on the extent to which natal experience influences host use. Although species that are not influenced by natal experience may be less likely to switch to nontarget hosts, species that are sensitive to such experience may be able to be trained to respond to target hosts that they do not historically use. Similarly, reintroduction strategies in conservation should be influenced by whether or not the species' habitat choices are influenced by natal experience (Stamps and Swaisgood 2007). If the species is influenced by natal experience, prerelease housing must be carefully designed to resemble the postrelease habitat. On the other hand, it may be possible to rear animals that are insensitive to early experience more efficiently, without the extra cost of preparing housing or food that is similar to what the animals will encounter upon release (e.g., Steele et al. 1989).

I hope that the data provided in this paper and the accompanying online tables will serve as a resource for future research into this topic by indicating which groups of animals are currently understudied, and also by providing expected effect sizes that can be used in statistical power estimation for efficiently designed studies. Furthermore, I hope that the adaptive hypotheses laid out in the final section can be used as a framework for hypothesis testing and for exploring adaptive reasons for inter- and intra-species variation in the effect of natal experience on habitat choice.

\section{ACKNOWLEDGMENTS}

My thanks to Judy Stamps, Tom Hahn, Sergey Nuzhdin, Karen Mabry, Dan Papaj, Emilie Snell-Rood, Jeff Oliver, Katy Prudic, Nicole Ferguson, Kristin Hultgren, John Wiens, and two anonymous reviewers for many helpful comments on previous versions of this manuscript.

\section{REFERENCES}

Akhtar Y., Isman M. B. 2003. Larval exposure to oviposition deterrents alters subsequent oviposition behavior in generalist, Trichoplusia $n i$ and specialist, Plutella xylostella moths. Journal of Chemical Ecology 29(8):1853-1870.

Allemang A., Petren K. 2004. Innate and acquired ecologically relevant behavior of the mourning gecko (Lepidodactylus lugubris). Paper presented at the annual meeting of the Animal Behavior Society, June 2004, in Oaxaca, Mexico.

Anderson P., Hilker M., Löfqvist J. 1995. Larval diet influence on oviposition behaviour in Spodoptera littoralis. Entomologia Experimentalis et Applicata 74(1): 71-82.

Antonov A., Stokke B. G., Moksnes A., Røskaft E. 2006. Egg rejection in marsh warblers (Acrocephalus palustris) heavily parasitized by common cuckoos (Cuculus canorus). Auk 123(2):419-430.

Armstrong J. D., de Belle J. S., Wang Z., Kaiser K. 1998. Metamorphosis of the mushroom bodies; large-scale rearrangements of the neural substrates for associative learning and memory 
in Drosophila. Learning and Memory 5(1-2):102114.

Arvedlund M., McCormick M. I., Fautin D. G., Bildsøe M. 1999. Host recognition and possible imprinting in the anemonefish Amphiprion melanopus (Pisces: Pomacentridae). Marine Ecology Progress Series 188:207-218.

Arvedlund M., Nielsen L. E. 1996. Do the anemonefish Amphiprion ocellaris (Pisces: Pomacentridae) imprint themselves to their host sea anemone Heteractis magnifica (Anthozoa: Actinidae)? Ethology 102:197-211.

Baker M. B. 2004. Sex biased state dependence in natal dispersal in desert isoponds, Hemilepistus reaumuri. Journal of Insect Behavior 17(5):579-598.

Barron A. B. 2001. The life and death of Hopkins' host-selection principle. Journal of Insect Behavior 14(6):725-737.

Barron A. B., Corbet S. A. 1999. Preimaginal conditioning in Drosophila revisited. Animal Behaviour 58(3):621-628.

Barton Browne L., Withers T. M. 2002. Time-dependent changes in the host-acceptance threshold of insects: implications for host specificity testing of candidate biological control agents. Biocontrol Science and Technology 12(6):677-693

Begg C. B., Mazumdar M. 1994. Operating characteristics of a rank correlation test for publication bias. Biometrics 50(4):1088-1101.

Beltman J. B., Haccou P. 2005. Speciation through the learning of habitat features. Theoretical Population Biology 67(3):189-202.

Beltman J. B., Haccou P., ten Cate C. 2004. Learning and colonization of new niches: a first step toward speciation. Evolution 58(1):35-46.

Bernays E. A., Bright K. L. 1993. Mechanisms of dietary mixing in grasshopppers: a review. Comparative Biochemistry and Physiology, Part A: Physiology 104(1):125-131.

Bernays E. A., Weiss M. R. 1996. Induced food preferences in caterpillars: the need to identify mechanisms. Entomologia Experimentalis et Applicata 78(1): $1-8$.

Bjorksten T. A., Hoffmann A. A. 1995. Effects of preadult and adult experience on host acceptance in choice and non-choice tests in two strains of Trichogramma. Entomologia Experimentalis et Applicata $76(1): 49-58$.

Bjorksten T. A., Hoffmann A. A. 1998a. Plant cues influence searching behaviour and parasitism in the egg parasitoid Trichogramma nr. brassicae. Ecological Entomology 23(4):355-362.

Bjorksten T. A., Hoffmann A. A. 1998b. Separating the effects of experience, size, egg load, and genotype on host response in Trichogramma (Hymenoptera: Trichogrammatidae). Journal of Insect Behavior 11(1):129-148.
Bossart J. L., Scriber J. M. 1999. Preference variation in the polyphagous tiger swallowtail butterfly (Lepidoptera: Papilionidae). Environmental Entomology 28(4):628-637.

Brooke M. de L., Davies N. B. 1991. A failure to demonstrate host imprinting in the cuckoo Cuculus canorus and alternative hypotheses for the maintenance of egg mimicry. Ethology 89(2):154166.

Burghardt G. M., Hess E. H. 1966. Food imprinting in the snapping turtle, Chelydra serpentina. Science 151: 108-109.

Cadieu N., Cadieu J.-C., El Ghadraoui L., Grimal A., Lambouf Y. 1999. Conditioning to ethanol in the fruit fly—a study using an inhibitor of ADH. Journal of Insect Physiology 45(6):579-586.

Cassidy M. D. 1978. Development of an induced food plant preference in the Indian stick insect, Carausius morosus. Entomologia Experimentalis et Applicata 24(3):287-293.

Caubet Y., Jaisson P. 1991. A post-eclosion early learning involved in host recognition by Dinarmus basalis rondani (Hymenoptera: Pteromalidae). Animal Behaviour 42(6):977-980.

Chow J. K., Akhtar Y., Isman M. B. 2005. The effects of larval experience with a complex plant latex on subsequent feeding and oviposition by the cabbage looper moth: Trichoplusia ni (Lepidoptera: Noctuidae). Chemoecology 15(3):129-133.

Chuche J., Xuéreb A., Thiéry D. 2006. Attraction of Dibrachys cavus (Hymenoptera: Pteromalidae) to its host frass volatiles. Journal of Chemical Ecology 32(12):2721-2731.

Cunningham J. P., Jallow M. F. A., Wright D. J., Zalucki M. P. 1998. Learning in host selection in Helicoverpa armigera (Hübner) (Lepidoptera: Noctuidae). Animal Behaviour 55(1):227-234.

Davis J. M. 2007. Preference or desperation? Distinguishing between the natal habitat's effects on habitat choice. Animal Behaviour 74(1):111-119.

Davis J. M., Stamps J. A. 2004. The effect of natal experience on habitat preferences. Trends in Ecology and Evolution 19(8):411-416.

Dejean A. 1990. Influence of the preimaginal and precocious environment on the choice of the nest in the ant Pachycondyla villosa (Fabr.). Behavioural Processes 21(2-3):107-125.

Desbuquois C., Daguzan J. 1995. The influence of ingestive conditioning on food choices in the land snail Helix aspersa Müller (Gastropoda: Pulmonata: Stylommatophora). Journal of Molluscan Studies 61(3):353-360.

Djieto-Lordon C., Dejean A. 1999a. Tropical arboreal ant mosaics: innate attraction and imprinting determine nest site selection in dominant ants. Behavioral Ecology and Sociobiology 45(3-4):219-225.

Djieto-Lordon C., Dejean A. 1999b. Innate attraction 
supplants experience during host plant selection in an obligate plant-ant. Behavioural Processes 46(3):181-187.

Facknath S., Wright D. J. 2007. Is host selection in leafminer adults influenced by pre-imaginal or early adult experience? Journal of Applied Entomology 131(8):505-512.

Forister M. L. 2004. Oviposition preference and larval performance within a diverging lineage of lycaenid butterflies. Ecological Entomology 29(3):264-272.

Gandolfi M., Mattiacci L., Dorn S. 2003a. Preimaginal learning determines adult response to chemical stimuli in a parasitic wasp. Proceedings of the Royal Society of London, Series B: Biological Sciences 270(1533): 2623-2629.

Gandolfi M., Mattiacci L., Dorn S. 2003b. Mechanisms of behavioral alterations of parasitoids reared in artificial systems. Journal of Chemical Ecology 29(8): 1871-1887.

Glück E. 1984. Habitat selection in birds and the role of early experience. Zeitschrift für Tierpsychologie 66: 45-54.

Gotthard K., Nylin S. 1995. Adaptive plasticity and plasticity as an adaptation: a selective review of plasticity in animal morphology and life history. Oikos 74:3-17.

Greenberg R. 1984. Neophobia in the foraging-site selection of a neotropical migrant bird: an experimental study. Proceedings of the National Academy of Sciences USA 81(12):3778-3780.

Grünberger S., Leisler B. 1990. Innate and learned components in the habitat selection of coal tits (Parus ater). Journal für Ornithologie 131(4):460-464.

Gurevitch J., Hedges L. V. 1999. Statistical issues in ecological meta-analyses. Ecology 80(4):1142.

Gutiérrez-Ibáñez C., Villagra C. A., Niemeyer H. M. 2007. Pre-pupation behaviour of the aphid parasitoid Aphidius ervi (Haliday) and its consequences for pre-imaginal learning. Naturwissenschaften 94(7)595600.

Hanski I., Singer M. C. 2001. Extinction-colonization dynamics and host-plant choice in butterfly metapopulations. American Naturalist 158(4):341-353.

Haughland D. L., Larsen K. W. 2004a. Ecology of North American red squirrels across contrasting habitats: relating natal dispersal to habitat. Journal of Mammalogy 85(2):225-236.

Haughland D. L., Larsen K. W. 2004b. Exploration correlates with settlement: red squirrel dispersal in contrasting habitats. Journal of Animal Ecology 73(6):1024-1034.

Hedrick P. W. 1990. Genotypic-specific habitat selection: a new model and its application. Heredity 65(2):145-149.

Hedrick P. W., Ginevan M. E., Ewing E. P. 1976. Genetic polymorphism in heterogeneous environments. Annual Review of Ecology and Systematics 7:1-32.
Heinz C. A., Feeny P. 2005. Effects of contact chemistry and host plant experience in the oviposition behaviour of the eastern black swallowtail butterfly. Animal Behaviour 69(1):107-115.

Hepper P. G., Waldman B. 1992. Embryonic olfactory learning in frogs. Quarterly Journal of Experimental Psychology Section B: Comparative and Physiological Psychology 44(3-4):179-197.

Hérard F., Keller M. A., Lewis W. J., Tumlinson J. H. 1988. Beneficial arthropod behavior mediated by airborne semiochemicals. III. Influence of age and experience on flight chamber responses of Microplitis demolitor Wilkinson. Journal of Chemical Ecology 14(7):1583-1596.

Hershberger W. A., Smith M. P. 1967. Conditioning in Drosophila melanogaster. Animal Behaviour 15(23):259-262.

Hoffmann A. A. 1988. Early adult experience in Drosophila melanogaster. Journal of Insect Physiology 34(3):197204.

Hoffmann A. A., Turelli M. 1985. Distribution of Drosophila melanogaster on alternative resources: effects of experience and starvation. American Naturalist $126(5)$ :662-679.

Honda J. Y., Walker G. P. 1996. Olfactory response of Anagrus nigriventris (Hym.: Mymaridae): effects of host plant chemical cues mediated by rearing and oviposition experience. Entomophaga 41(1):3-13.

Honza M., Moksnes A., Røskaft E., Stokke B. G. 2001. How are different common cuckoo Cuculus canorus egg morphs maintained? An evaluation of different hypotheses. Ardea 89(2):341-352.

Hopkins A. D. 1917. A discussion of C. G. Hewitt's paper on 'insect behavior.' Journal of Economic Entomology 10:92-93.

Hora K. H., Roessingh P., Menken S. B. J. 2005. Inheritance and plasticity of adult host acceptance in Yponomeuta species: implications for host shifts in specialist herbivores. Entomologia Experimentalis et Applicata 115(1):271-281.

Hovanitz W. 1969. Inherited and/or conditioned changes in host-plant preference in Pieris. Entomologia Experimentalis et Applicata 12:729-735.

Hovanitz W., Chang V. C. S. 1963. Ovipositional preference tests with Pieris. Journal of Research on the Lepidoptera 2(3):185-200.

Immelmann K. 1975. Ecological significance of imprinting and early learning. Annual Review of Ecology and Systematics 6:15-37.

Jaenike J. 1982. Environmental modification of oviposition behavior in Drosophila. American Naturalist $119(6): 784-802$.

Jaenike J. 1988. Effects of early adult experience on host selection in insects: some experimental and theoretical results. Journal of Insect Behavior 1(1): 3-15.

Jaisson P. 1980. Environmental preference induced 
experimentally in ants (Hymenoptera: Formicidae). Nature 286:388-389.

Johnson C. 1966. Environmental modification of habitat selection in adult damselflies. Ecology 47(4): 674-676.

Kaur J. S., Lai Y. L., Giger A. D. 2003. Learning and memory in the mosquito Aedes aegypti shown by conditioning against oviposition deterrence. Medical and Veterinary Entomology 17(4):457-460.

Kerpel S. M., Moreira G. R. P. 2005. Absence of learning and local specialization on host plant selection by Heliconius erato. Journal of Insect Behavior 18(3): 433-452.

Kester K. M., Barbosa P. 1994. Behavioral responses to host foodplants of two populations of the insect parasitoid Cotesia congregata (Say). Oecologia 99(12):151-157.

Kirmse W. 2001. Wiedereinbürgerung baumbrütender Wanderfalken (Falco peregrinus) in Mitteleuropa. Zeitschrift für Jagdwissenschaft 47:165-177.

Klopfer P. H. 1963. Behavioral aspects of habitat selection: the role of early experience. Wilson Bulletin 75(1):15-22.

Kölliker-Ott U. M., Bigler F., Hoffmann A. A. 2003. Does mass rearing of field collected Trichogramma brassicae wasps influence acceptance of European corn borer eggs? Entomologia Experimentalis et Applicata 109(3):197-203.

Lecomte C., Thibout E. 1993. Pre- and post-imaginal experience in a specialist parasitoid Diadromus pulchellus (Hym.: Ichneumonidae). Entomophaga 38(2): 175-184.

Ley H.-W. 1988. Verhaltensontogenese der Habitatwahl beim Teichrohrsänger (Acrocephalus scirpaceus). Journal Für Ornithologie 129(3):287-298.

Linn C., Jr., Feder J. L., Nojima S., Dambroski H. R., Berlocher S. H., Roelofs W. 2003. Fruit odor discrimination and sympatric host race formation in Rhagoletis. Proceedings of the National Academy of Sciences USA 100(20):11490-11493.

Liu S.-S., Li Y.-H., Liu Y.-Q., Zalucki M. P. 2005. Experience-induced preference for oviposition repellents derived from a non-host plant by a specialist herbivore. Ecology Letters 8(7):722-729.

Liu S.-S., Liu T.-X. 2006. Preimaginal conditioning does not affect oviposition preference in the diamondback moth. Ecological Entomology 31(4):307315.

Lushai G., Sherratt T. N., David O., Barro P. J., Maclean N. 1997. Host selection by winged summer females of the aphid Sitobion avenae. Entomologia Experimentalis et Applicata 85(3):199-209.

Mabry K. E., Stamps J. A. 2008. Dispersing brush mice prefer habitat like home. Proceedings of the Royal Society of London, Series B: Biological Sciences 275(1634): 543-548.
Manning A. 1967. "Pre-imaginal conditioning" in Drosophila. Nature 216:338-340.

Maynard Smith J. 1966. Sympatric speciation. American Naturalist 100(916):637-650.

McAuslane H. J., Vinson S. B., Williams H. J. 1990. Effect of host diet on flight behavior of the parasitoid Campoletis sonorensis (Hymenoptera: Ichneumonidae). Journal of Entomological Science 25:562570.

McCall P. J., Eaton G. 2001. Olfactory memory in the mosquito Culex quinquefasciatus. Medical and Veterinary Entomology 15(2):197-203.

McCall P. J., Kelly D. W. 2002. Learning and memory in disease vectors. Trends in Parasitology 18(10): $429-433$.

Monge J. P., Cortesero A. M. 1996. Tritrophic interactions among larval parasitoids, bruchids and Leguminosae seeds; influence of pre- and postemergence learning on parasitoids' response to host and host-plant cues. Entomologia Experimentalis et Applicata 80(1):293-296.

Moore P. J., Moore A. J. 2001. Reproductive aging and mating: the ticking of the biological clock in female cockroaches. Proceedings of the National Academy of Sciences USA 98(16):9171-9176.

Morris R. J., Fellowes M. D. E. 2002. Learning and natal host influence host preference, handling time and sex allocation behaviour in a pupal parasitoid. Behavioral Ecology and Sociobiology 51(4): 386-393.

Mueller T. F. 1983. The effect of plants on the host relations of a specialist parasitoid of Heliothis larvae. Entomologia Experimentalis et Applicata 34(1): $78-84$.

Mushinsky H. R. 1976. Ontogenetic development of microhabitat preference in salamanders: the influence of early experience. Copeia 4:755-758.

Olsson P. O. C., Anderbrant O., Lofstedt C. 2006. Experience influences oviposition behaviour in two pyralid moths, Ephestia cautella and Plodia interpunctella. Animal Behaviour 72(3):545-551.

Ortega-Reyes L., Provenza F. D. 1993. Experience with blackbrush affects ingestion of shrub live oak by goats. Journal of Animal Science 71 (2):380-383.

Palmiter R. D. 1966. Absence of olfactory conditioning in an oligophagous insect, the corn earworm, Heliothis zea (Boddie). Animal Behaviour 14(2-3): 236-238.

Payne R. B., Payne L. L., Woods J. L., Sorenson M. D. 2000. Imprinting and the origin of parasite-host species associations in brood-parasitic indigobirds, Vidua chalybeata. Animal Behaviour 59(1):69-81.

Phillips W. M. 1977. Modification of feeding 'preference' in the flea-beetle, Haltica lythri (Coleoptera, Chrysomelidae). Entomologia Experimentalis et Applicata 21(1):71-80.

Potting R. P. J., Otten H., Vet L. E. M. 1997. Absence 
of odour learning in the stemborer parasitoid $\mathrm{Co}^{-}$ tesia flavipes. Animal Behaviour 53(6):1211-1223.

Provenza F. D., Balph D. F. 1988. Development of dietary choice in livestock on rangelands and its implications for management. Journal of Animal Science 66(9):2356-2368.

Ray S. 1999. Survival of olfactory memory through metamorphosis in the fly Musca domestica. Neuroscience Letters 259(1):37-40.

Rietdorf K., Steidle J. L. M. 2002. Was Hopkins right? Influence of larval and early adult experience on the olfactory response in the granary weevil Sitophilus granarius (Coleoptera: Curculionidae). Physiological Entomology 27(3):223-227.

Rojas J. C., Wyatt T. D. 1999. The role of pre- and post-imaginal experience in the host-finding and oviposition behaviour of the cabbage moth. Physiological Entomology 24(1):83-89.

Rosenberg M. S., Adams D. C., Gurevitch J. 2000. MetaWin: Statistical software for meta-analysis. CDROM. Sunderland (MA): Sinauer Associates.

Rozin P. 1976. The selection of foods by rats, humans, and other animals. Pages 21-76 in Advances in the Study of Behavior, Volume 6, edited by J. S. Rosenblatt et al. New York: Academic Press.

Sacks B. N., Brown S. K., Ernest H. B. 2004. Population structure of California coyotes corresponds to habitat-specific breaks and illuminates species history. Molecular Ecology 13(5):1265-1275.

Sargent T. D. 1965. The role of experience in the nest building of the zebra finch. Auk 82:48-61.

Schaden G. 1993. Exploration and neophobia in captive barn owls (Tyto alba guttata): the influence of early experience and familiarity. Egretta 36:67-77.

Sembene M., Delobel A. 2004. Myth or reality? The "Hopkins principle" in the case of the groundnut seed beetle, Caryedon serratus (Coleoptera, Bruchidae). Bulletin de la Société Entomologique de France 109(1):61-66.

Sheehan W., Shelton A. M. 1989. The role of experience in plant foraging by the aphid parasitoid Diaeretiella rapae (Hymenoptera: Aphidiidae). Journal of Insect Behavior 2(6):743-759.

Singer M. C., Vasco D., Parmesan C., Thomas C. D., Ng D. 1992. Distinguishing between 'preference' and 'motivation' in food choice: an example from insect oviposition. Animal Behaviour 44(3):463-471.

Slagsvold T., Wiebe K. L. 2007. Learning the ecological niche. Proceedings of the Royal Society of London, Series B: Biological Sciences 274(1606):19-23.

Smith M. A., Cornell H. V. 1979. Hopkins hostselection in Nasonia vitripennis and its implications for sympatric speciation. Animal Behaviour 27(2): 365-370.

Solarz S. L., Newman R. M. 2001. Variation in hostplant preference and performance by the milfoil weevil, Euhrychiopsis lecontei Dietz, exposed to na- tive and exotic watermilfoils. Oecologia 126(1):6675.

Stamps J. A., Blozis S. A. 2006. Effects of natal experience on habitat selection when individuals make choices in groups: a multilevel analysis. Animal Behaviour 71(3):663-672.

Stamps J. A., Davis J. M. 2006. Adaptive effects of natal experience on habitat selection by dispersers. $A n-$ imal Behaviour 72(6):1279-1289.

Stamps J. A., Davis J. M., Blozis S. A., Boundy-Mills K. L. 2007. Genotypic variation in refractory periods and habitat selection by natal dispersers. Animal Behaviour 74(3):599-610.

Stamps J. A., Krishnan V. V., Reid M. L. 2005. Search costs and habitat selection by dispersers. Ecology 86(2):510-518.

Stamps J. A., Swaisgood R. R. 2007. Someplace like home: experience, habitat selection and conservation biology. Applied Animal Behaviour Science 102(34):392-409.

Steele C. W., Grassman M. A., Owens D. W., Matis J. H. 1989. Application of decision theory in understanding food choice behavior of hatchling loggerhead sea turtles and chemosensory imprinting in juvenile loggerhead sea turtles. Experientia 45:202-205.

Steidle J. L. M., Reinhard J. 2003. Low humidity as a cue for habitat preference in the parasitoid Lariophagus distinguendus. BioControl 48(2):169-175.

Storeck A., Poppy G. M., van Emden H. F., Powell W. 2000. The role of plant chemical cues in determining host preference in the generalist aphid parasitoid Aphidius colemani. Entomologia Experimentalis et Applicata 97(1):41-46.

Tabashnik B. E., Wheelock H., Rainbolt J. D., Watt W. B. 1981. Individual variation in oviposition preference in the butterfly, Colias eurytheme. Oecologia 50(2):225-230.

Taylor C. E. 1976. Genetic variation in heterogeneous environments. Genetics 83(4):887-894.

Taylor C. E. 1986. Habitat choice by Drosophila pseudoobscura: the roles of genotype and of experience. $B e-$ havior Genetics 16(2):271-279.

Teuschl Y., Taborsky B., Taborsky M. 1998. How do cuckoos find their hosts? The role of habitat imprinting. Animal Behaviour 56(6):1425-1433.

Thacker R. W. 1996. Food choices of land hermit crabs (Coenobita compressus H. Milne Edwards) depend on past experience. Journal of Experimental Marine Biology and Ecology 199(2):179-191.

Thomas F., Liautard C., Cézilly F., Renaud F. 1998. A finite time horizon influences sequential mate choice in male Gammarus aequicauda (Amphipoda). Canadian Journal of Zoology 76(3):401-405.

Thorpe W. H. 1938. Further experiments on olfactory conditioning in a parasitic insect. The nature of the 
conditioning process. Proceedings of the Royal Society of London, Series B: Biological Sciences 126(844):370-397.

Thorpe W. H. 1939. Further studies on pre-imaginal olfactory conditioning in insects. Proceedings of the Royal Society of London, Series B: Biological Sciences $127(848): 424-433$.

Thorpe W. H., Jones F. G. W. 1937. Olfactory conditioning in a parasitic insect and its relation to the problem of host selection. Proceedings of the Royal Society of London, Series B: Biological Sciences 124(834):56-81.

Tissot M., Stocker R. F. 2000. Metamorphosis in Drosophila and other insects: the fate of neurons throughout the stages. Progress in Neurobiology 62(1):89-111.

Turelli M., Coyne J. A., Prout T. 1984. Resource choice in orchard populations of Drosophila. Biological Journal of the Linnean Society 22:95-106.

Turlings T. C. J., Tumlinson J. H., Lewis W. J., Vet L. E. M. 1989. Beneficial arthropod behavior mediated by airborne semiochemicals. VIII. Learning of host-related odors induced by a brief contact experience with host by-products in Cotesia marginiventris (Cresson), a generalist larval parasitoid. Journal of Insect Behavior 2(2):217-225.

Van Emden H. F., Sponagl B., Wagner E., Baker T., Ganguly S., Douloumpaka S. 1996. Hopkins' 'host selection principle,' another nail in its coffin. Physiological Entomology 21(4):325-328.

Vargas A., Anderson S. H. 1996. Effects of diet on captive black-footed ferret (Mustela nigripes) food preference. Zoo Biology 15(2):105-113.

Vet L. E. M. 1983. Host-habitat location through olfactory cues by Leptopilina clavipes (Hartig) (Hym: Eucoilidae), a parasitoid of fungivorous Drosophila: the influence of conditioning. Netherlands Journal of Zoology 33(3):225-248.

Vogl W., Taborsky M., Taborsky B., Teuschl Y., Honza M. 2002. Cuckoo females preferentially use specific habitats when searching for host nests. Animal Behaviour 64(6):843-850.

Vos M., Vet L. E. M. 2004. Geographic variation in host acceptance by an insect parasitoid: genotype versus experience. Evolutionary Ecology Research 6:1021-1035.

Walsh B. D. 1864. On phytophagic varieties and phytophagic species. Proceedings of the Entomological Society of Philadelphia 3:403-430.

Wecker S. C. 1963. The role of early experience in habitat selection by the prairie deer mouse, Peromyscus maniculatus bairdi. Ecological Monographs 33(4):307-325.

Wiens J. A. 1970. Effects of early experience on substrate pattern selection in Rana aurora tadpoles. Copeia 1970:543-548.

Wiklund C. 1974. Oviposition preference in Papilio machaon in relation to the host plants of the larvae. Entomologia Experimentalis et Applicata 17(2):189198. 